\title{
Right Turn Coeficient Evaluation Analysis on Intersection capasity formula at Indonesia Highway Capasity Manual 1997 Using Vehicle Tracking Simulation
}

\author{
Basuki Kami Hari ${ }^{1,}$, and Purwanto Djoko ${ }^{1}$ \\ ${ }^{1}$ Researcher at Civil Engineering Department, Diponegoro University, Semarang, Indonesia
}

\begin{abstract}
The aims of this study are to evaluate the the right-turn coefficients at intersection capasity formula by Indonesia Highway Capacity Manual (MKJI 1997). Therefore, it is necessary for analysis that examines right-turn coefficient values in intersection capacity function. The simulation with many various geometric intersections defined by many scenarios using vehicle tracking application program, which increase the space maneuver vehicle at the intersection includes: 1) widen approach lane; 2) add a right-turn lane; and 3) backward median in each approach. Intersection performance Analysis will produce degree of saturation that is affected by right-turn coefficient according to the simulated vehicle maneuver using new formula. The study can be concluded that the intersection changes the right-turn factor adjustment which was originally set with the value based on linear function being a log function. According to the new function, Prt Less 2,5\% right turn vehicle make significant decrease of intersection capacity, that why, it makes many conflict based on opposite traffic from other approach. In the other side, if Prt more then $2,5 \%$, it makes increase intersection capacity because intersection space used to right turn vehicles.
\end{abstract}

Keywords: right-turn coefficient, vehicle maneuver, IHCM 1997

\section{Introduction}

Semarang as capital city of Central Java has pretty high vehicle movement activity, and to provide a good transportation climate, it needs a good intersection to serve vehicle movement which pass through it. Intersection in Semarang in many cases cannot provide a good traffic flow movement yet, especially when it comes to freight vehicle movement. It is indicated by delay, which is probably caused by bad traffic control or inadequate intersection/right-turn geometric [2, 4]. Therefore, it needs further analysis about intersection and right-turn performances and freight vehicle maneuver by taking case study at Semarang Northern Ring Road. Right-turn which represent main intersections for freight vehicle movement route.

\footnotetext{
*Corresponding author: basuki.kh@gmail.com
} 


\section{Methodology}

Analysis starts by doing traffic counting survey and geometric data collecting on each case study sites. Intersection's performance is analyzed using SIG-I - SIG-V forms [3] from Manual Kapasitas Jalan Indonesia 1997 to generates intersection's performance parameters such as capacity, delay and degree of saturation for each intersection's approach. Right-turn performance is analyzed using queue modelling method to generates right-turn intensity value, average queue waiting time and average number of vehicle in the queue $[4,5]$. After doing performance analysis on existing intersections and right-turn, vehicle maneuver simulation can be performed using vehicle tracking simulation from Autodesk which will generates vehicle maneuver route and its ellapsed time to do that maneuver [1]. Based on those analysis and simulation, several optimization steps are taken to repair or improve intersection and right-turn performances especially due to heavy vehicle maneuver by changing its existing geometrics to be efficiently able to serve vehicle maneuver on it. Optimization result then evaluated to see the performance difference as well as the conclusions drawn based on the analysis and optimization.

\section{Data Analysis}

\subsection{Performance Analysis at Northern Ring Road Intersection}

Traffic survey data is processed in order to obtain traffic flow data for each hour interval and the biggest traffic flow data value will be used as intersection's traffic peak hour $[2,3]$. In Northern Ring Road Intersection, traffic flow peak hour is at 4.15-5.15 pm. Northern Ring Road Intersection performance analysis generates intersection's capacity (C), degree of saturation (DS), vehicles queue and delay (D) as shown in Table 1.

Table 1. Intersection Performance Analysis Parameters

\begin{tabular}{|c|c|c|c|c|c|c|c|c|}
\hline \multirow{2}{*}{ Approach } & $\begin{array}{c}\text { Traffic } \\
\text { Flow }\end{array}$ & $\begin{array}{c}\text { Effective } \\
\text { Width }\end{array}$ & $\begin{array}{c}\text { Green } \\
\text { Ratio }\end{array}$ & $\begin{array}{c}\text { Saturated } \\
\text { Flow }\end{array}$ & Capacity & $\begin{array}{c}\text { Degree of } \\
\text { Saturation }\end{array}$ & $\begin{array}{c}\text { Queue } \\
\text { Length }\end{array}$ & Delay \\
\cline { 2 - 9 } & Q & We & GR & S & C & DS & QL & D \\
\hline East & 319,9 & 7 & 0,144 & 2778,750 & 400,781 & 0,798 & 45,714 & 59,856 \\
\hline South & 1881,5 & 11,5 & 0,327 & 6096,150 & 1992,972 & 0,944 & 135,565 & 50,806 \\
\hline West & 291,8 & 7 & 0,144 & 3087,500 & 445,313 & 0,655 & 40,000 & 49,739 \\
\hline North & 1349,6 & 10,5 & 0,365 & 5566,050 & 2033,749 & 0,664 & 89,524 & 31,839 \\
\hline
\end{tabular}

Based on that result, Northern Ring Road Intersection cannot serve the existing traffic flow yet, which is showed by degree of saturation for south approach $=0,94(\mathrm{DS}>0,85)$.

\subsection{Heavy vehicle maneuver simulation on existing geometric condition}

Figure 1 below has shown vehicle maneuver simulation result on each Northern Ring Road Intersection's approach. Based on vehicle tracking simulation, Northern Ring Road Intersection's existing geometric can serve heavy vehicle maneuver on it, but with several maneuver simulation test it could be optimized to get a more efficient maneuver route by 
changing intersections geometry aiming for reduced heavy vehicle maneuver ellapsed time to enchance intersections performance.
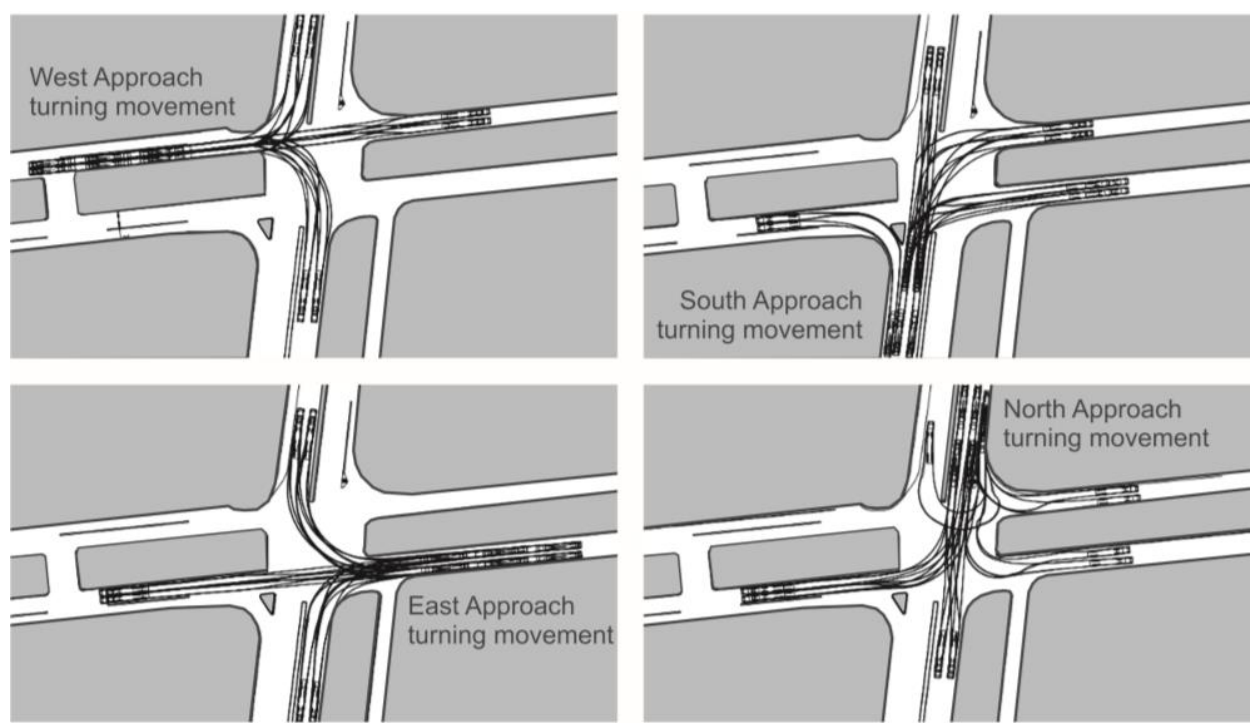

Fig. 1. Vehicle Maneuver Simulation on Existing Northern Ring Road Intersection Geometric in each approach

\subsection{Intersection and Right-turn Optimization}

Intersection optimization to serve the existing traffic flow is done by rearranging its signal time and make a turn around restriction. Table 2 shows intersection performance analysis result after signal time optimization.

Table 2. Intersection Performance Analysis Parameters with Signal Time Optimization

\begin{tabular}{|c|c|c|c|c|c|c|c|c|}
\hline \multirow{2}{*}{ Approach } & $\begin{array}{c}\text { Traffic } \\
\text { Flow }\end{array}$ & $\begin{array}{c}\text { Effective } \\
\text { Width }\end{array}$ & $\begin{array}{c}\text { Green } \\
\text { Ratio }\end{array}$ & $\begin{array}{c}\text { Saturated } \\
\text { Flow }\end{array}$ & Capacity & $\begin{array}{c}\text { Degree of } \\
\text { Saturation }\end{array}$ & $\begin{array}{c}\text { Queue } \\
\text { Length }\end{array}$ & Delay \\
\cline { 2 - 9 } & Q & We & GR & S & C & DS & QL & D \\
\hline East & 694,7 & 7 & 0,288 & 2778,750 & 801,5625 & 0,866 & 38,486 & 50,88 \\
\hline South & 622,2 & 11,5 & 0,231 & 6096,150 & 1406,804 & 0,442 & 135,565 & 38,00 \\
\hline West & 448,7 & 7 & 0,173 & 3087,500 & 534,375 & 0,840 & 31,257 & 59,25 \\
\hline North & 964,8 & 10,5 & 0,346 & 5566,050 & 1926,71 & 0,501 & 82,076 & 30,33 \\
\hline
\end{tabular}

After signal time optimization, to optimize it even more due to heavy vehicle maneuver geometric optimization can be done as follows: 1) Bridge widening from 41,3 meters to 51,3 meters; 2) North and east median tip adjustment. Figure 2 shows geometric optimization for Northern Ring Road Intersection [2]. 


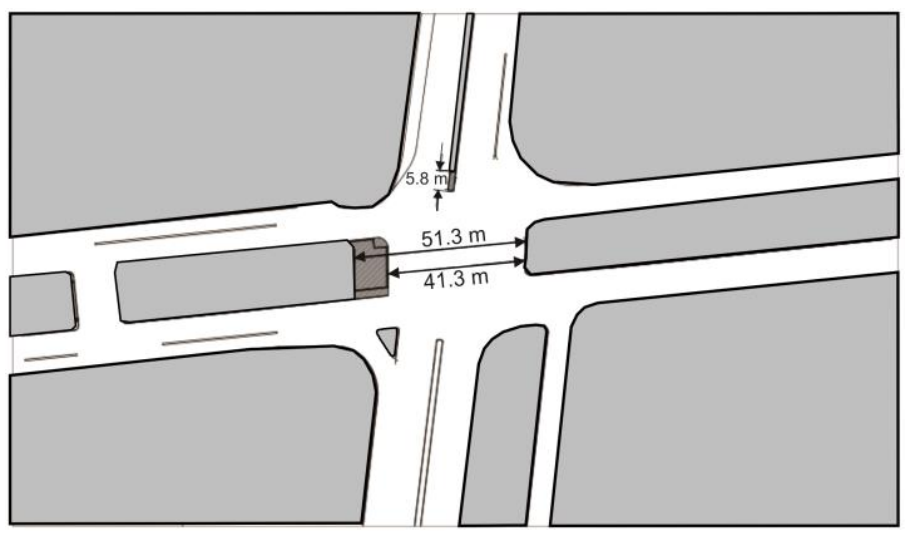

Fig. 2. Geometric Optimization Plan for Northern Ring Road Intersection

With reduced turn right maneuver ellapsed time, delay on each approach is reduced too and affecting in increased turn right factor (turn right vehicle got a reduced ellapsed time to do the maneuver due to geometric optimization and it makes intersection can afford more number of turning right vehicle. It is in line with the concept of right turn magnification factor (Frt) according to Manual Kapasitas Jalan Indonesia (MKJI 1997) [3] that turning. Vehicle maneuver elapsed time difference caused by geometric optimization shown in Table 3.

Table 3. Vehicle Maneuver Ellapsed Time Comparison Before and After Geometric Optimization for Northern Ring Road Intersection

\begin{tabular}{|c|c|c|}
\hline \multirow{2}{*}{ Heavy Vehicle Maneuver } & \multicolumn{2}{|c|}{ Ellapsed Time (s) } \\
\cline { 2 - 3 } & Existing & Optimized \\
\hline West-RT & 27,7 & 25,4 \\
\hline North-RT & 28,1 & 26,9 \\
\hline East-RT & 25,6 & 24,0 \\
\hline South-RT & 31,5 & 30,6 \\
\hline
\end{tabular}

\section{Discussion}

\subsection{Intersection Performance Comparison}

Right vehicle has a tendency to cut out the center line of the road before turning right so the number of turning right vehicles could be increased. By increased right turn factor, saturated flow is also increased and it affecting in increased intersection approach's capacity. This additional capacity ends up reducing intersection's degree of saturation. Northern Ring Road Intersection performance analysis result after geometric optimization is shown in Table 4. As comparison for that value, Table 5 below shows the performance parameters comparison between only signal time optimized intersection and after geometric optimization is taken. 
Table 4. Performance Analysis Result of Geometric Optimized Northern Ring Road Intersection

\begin{tabular}{|c|c|c|c|c|c|c|c|c|}
\hline \multirow{2}{*}{ Approach } & $\begin{array}{c}\text { Traffic } \\
\text { Flow }\end{array}$ & $\begin{array}{c}\text { Effective } \\
\text { Width }\end{array}$ & $\begin{array}{c}\text { Green } \\
\text { Ratio }\end{array}$ & $\begin{array}{c}\text { Saturated } \\
\text { Flow }\end{array}$ & Capacity & $\begin{array}{c}\text { Degree of } \\
\text { Saturation }\end{array}$ & $\begin{array}{c}\text { Queue } \\
\text { Length }\end{array}$ & Delay \\
\cline { 2 - 9 } & Q & We & GR & S & C & DS & QL & D \\
\hline East & 694,7 & 7 & 0,288 & 2778,750 & 801,5625 & 0,866 & 38,486 & 50,88 \\
\hline South & 622,2 & 11,5 & 0,231 & 6096,150 & 1406,804 & 0,442 & 135,565 & 38,00 \\
\hline West & 448,7 & 7 & 0,173 & 3087,500 & 534,375 & 0,840 & 31,257 & 59,25 \\
\hline North & 964,8 & 10,5 & 0,346 & 5566,050 & 1926,71 & 0,501 & 82,076 & 30,33 \\
\hline
\end{tabular}

Table 5. Performance Parameters Comparison Between Before and After Geometric Optimization on Northern Ring Road Intersection

\begin{tabular}{|c|c|c|c|c|c|c|}
\hline \multirow{2}{*}{ Approach } & \multicolumn{2}{|c|}{ Degree of Saturation } & \multicolumn{2}{c|}{ Queue Length } & \multicolumn{2}{c|}{ Delay } \\
\cline { 2 - 7 } & Existing & Optimized & Existing & Optimized & Existing & Optimized \\
\hline East & 0,798 & 0,866 & 45,714 & 38,486 & 59,856 & 50,88 \\
\hline South & 0,944 & 0,442 & 135,565 & 135,565 & 50,806 & 38,00 \\
\hline West & 0,655 & 0,840 & 40,000 & 31,257 & 49,739 & 59,25 \\
\hline North & 0,664 & 0,501 & 89,524 & 82,076 & 31,839 & 30,33 \\
\hline
\end{tabular}

Based on that optimizations, it signifies that intersection performance is increased by rearranging traffic signal time, restricting turn around movement and repairing intersection's geometric in order to optimizing heavy vehicle maneuver on intersection.

\subsection{Frt Function}

According to MKJI 1997 [3] there is graph between right turning factor (Frt) with right turn ratio (Prt). The graph is in the form of a linear line upwards. The value is obtained from the quotient between the number of vehicle volumes that turn right and the total volume of vehicles in each approach. From the calculation in the graph of Prt and Frt relationship as Figure 3 as follows:

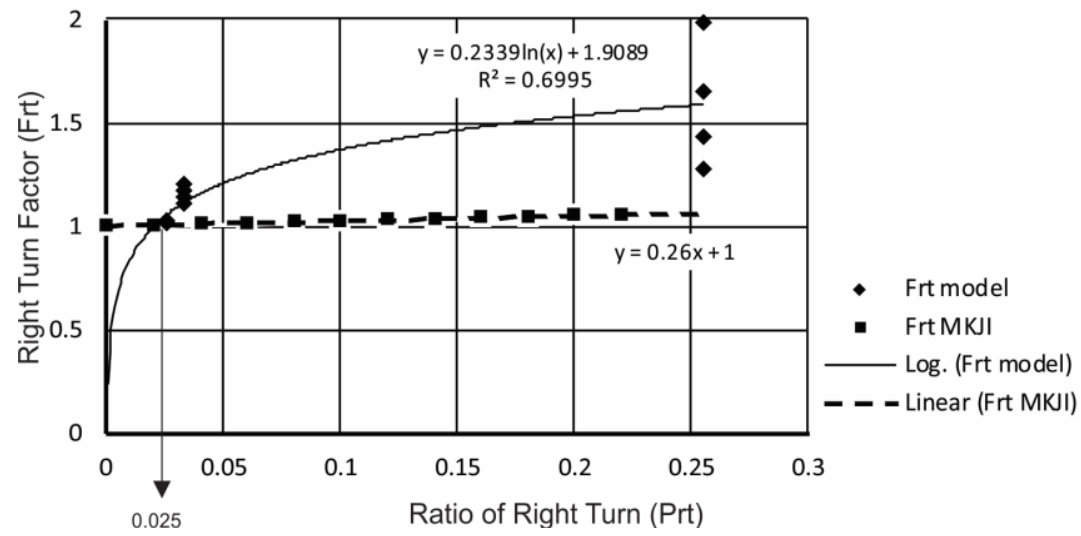

Fig. 3. The Relation Between Frt and Prt 
The dotted line shows the graph of the relationship between Prt and Frt according to MKJI 1997 in the form of linear [3]. While on the black line shows the graph of the relationship between Prt and Frt according to survey results in the field in the form of logarithm. It can be seen from the graph that the right turn ratio is $2.5 \%$, then Frt is worth. It means that if there is one right turn vehicle, right turn ratio is worth $2,5 \%$. On the graph can also be concluded that the value of Frt is not worth 0 . If there are a few vehicles that turns right, then it can decrease the performance of intersection capacity. Otherwise, if there are many vehicles that turn right, it can improve the performance of intersection capacity or the intersection has accommodated the right turn well. So, it can be concluded that the northern Ring Road intersection changes the right turning factor adjustment which was originally set with the value of 1 being a function $y=0.2339 \ln (x)+1.9089$ with $\mathrm{R} 2=0.6995$.

\section{Conclusion}

Existing intersection results on Northern Ring Road Intersection performance analysis shows value of DS (degree of saturation) for east approach is 0,80 , south approach 0,94 , west approach 0,66 and north approach is 0,66 . DS of south approach exceeding the maximum standard value of intersection's DS which is 0,85 . Vehicle maneuver simulation on existing intersection and using vehicle tracking simulation gives results as follows, Northern Ring Road Intersection geometrics can still be optimized to serve vehicle maneuver more efficiently in order to improve intersection's performance. So, it can be concluded that the northern Ring Road intersection changes the right-turn factor adjustment which was originally set with the value based on linear function Frt $=0,26 \mathrm{Prt}+1$ being a $\log$ function $\mathrm{Frt}=0.2339 \mathrm{ln}$ (Prt) +1.9089 with $\mathrm{R} 2=0.6995$. According to the new function, Prt less then 0,025 the meaning is that $2,5 \%$ vehicle in right turn depend from all traffic approach. Less $2,5 \%$ right turn vehicle make significant decrease of intersection capacity, that why, it makes many conflict based on opposite traffic from other approach. In the other side, if Prt more then $2,5 \%$, it makes increase intersection capacity because intersection space used to right turn vehicles. The formula need verification and validation step to according on study cases in variate intersection type. Basically, it is on going research to get the best function.

\section{Reference}

1. Autodesk, Vehicle Tracking Manual Drive, http://help.autodesk.com/view/VEHTRK/2017/ (2017)

2. Direktorat Jenderal Bina Marga, Standar Perencanaan Geometrik Untuk Jalan Perkotaan, Jakarta (2004)

3. Direktorat Jenderal Bina Marga, Manual Kapasitas Jalan Indonesia. Kementerian Pekerjaan Umum, Jakarta (1997)

4. May, A. D., Traffic Flow Fundamentals, New Jersey: Prentice Hall (1990)

5. Ortúzar, J. D., \& Willumsen, G. L., Modelling Transport, West Sussex: John Wiley \& Sons (2011) 